venient model for further enzymatic studies. The results of an examination of the action of pancreatic elastase on crude polysaccharide suggest that elastase is an oxidizing enzyme.

Dr. H. Saxl and Dr. G. N. Graham, in the third paper, gave details of an interesting histochemical and biochemical study of the Ehlers Danlos syndrome. The work has been carried out during the past five years on biopsy specimens from two patients suffering from this condition. One biopsy from each of these patients afforded the material for electron. microscope studies previously reported. Histological examination of a lesion from one of the patients (a boy aged $3 \frac{1}{2}$ years) showed an increased amount of elastic-staining material, paralleled by a decrease of collagen. The lesion was highly metachromatic and the periodic-acid - Schiff reaction was very positive. The elastic tissue from the lesion and that of the "apparently healthy skin" surrounding it was found to be resistant to elastase. Drs. Saxl and Graham directed attention to the fact that elastase can be inhibited by a component of normal serum. The elastase-inhibiting effect of the serum of Ehlers Danlos patients was found to be quantitatively increased over that of normal serum.

Although attempts to isolate the component or components of sorum responsible for such inhibition of elastase by means of chromatography on an ionexchange resin column have been made, the results so far obtained have been rather equivocal. However, there are indications that the inhibitory agent is a high-molecular-weight component associated with the globular serum proteins. Drs. Saxl and Graham have also made a study of the effect of the inhibitor using fresh ox ligamentum nuchæ as the elastic substrate and have found a loss of meta. chromasia if the enzyme, the substrate and the inhibitor are incubated together. There is, however, no loss of metashromasia if each of these components is pormitted to act in turn on the ligamentum nuchæ. There is an increased susceptibility of elastic tissue to elastase in senile elastosis, and the elastic fibres of the human carotid artery and of the sorta are dis. solved by elastase at a greater speed with advancing age. In the serum of patients belonging to the agegroup in which there is a high incidence of arteriosclerosis, there is a reduced concentration of serum inhibitor for elastase which is related to a low concentration of the enzyme in the pancreas.

In vitro experiments have indicated that the inhibitor has a twofold biological action : first, the control of the enzyme elastase in the formation of degradation products; and secondly, the absorption of metachromatic mucoid and elastic-staining substances. From the work of Karczmar and S. M. Rose, who have shown that, in vivo, differential development can be correlated with inhibition, it would not seem too unlikely to suggest that the elastase inhibitor can be an essential factor in the formation of elastic fibre.

The final paper, by Dr. David Hall, dealt with the dependence of equilibria between connective tissue components on age. He said that the structural components of connective tissue are particularly resistant to metabolic reactions, but must be maintained at their normal concentration by the simultaneous presence of anabolic and catabolic enzyme systems and their appropriate inhibitors. Age changes in the susceptibility of the various structures to attack by their specific enzymes can be coupled with variations in concentration of those few enzyme systems which have as yet boen identified. A full assessment of the equilibria between the various components can only be made when studies of tissue, enzyme and inhibitor from the same animal and from the same age-group are made. As a preliminary to these studies, it has been necessary to examine the chemical reactivity of the tissue components.

Alkali treatment of collagen results in the extraction of small quantities of protein under conditions which give marked production of elastin-like material when examined under the electron microscope. The protein is, in certain circumstances, rich in hydroxyproline and arginine, two amino-acids which one would expect to be extracted, if collagen were to change to elastin. In the case of young collagen, this hydroxyproline-rich material is extracted during the early period of treatment, whereas the extract from old collagen does not contain a high hydroxyproline content until longer periods of extraction have occurred.

Bassed on these results, and those stemming from the observations of the other workers in the group, it is possible to devise a hypothesis for a similar in vivo synthesis of elastin via collagen. If this is done, many of the hitherto unexplained questions concerning connective tissue can be solved: for example, the absence of an elastoblast, the variations in chemical composition of elastins of various agegroups, and the appearance of elastic staining materials which are really dissimilar, in senile elastosis and the Ehlers Danlos syndrome. It was stressed by Dr. Hall that this is only a hypothesis, but that it would act as a starting-point for the discussion of age relationships of collagen and elastin, by permitting them to be considered as a single unit rather than as two diverse structures which merely share a common site.

G. H. BOURNE

\section{NON-DESTRUCTIVE TESTING OF MATERIALS AND STRUCTURES}

$T$

HE French and English editions of the report* on the symposium on "Non-Destructive Testing of Materials and Structures", held in Paris in January 1954 by the Réunion Internationale des Laboratoires d'Essais et de Recherches sur les Matériaux et les Constructions, include thirty-nine papers from fourteen countries, some of the discussion and a bibliography containing references to fifty-five papers on non-destructive testing. The symposium was very largely concerned with the testing of concrete, and the scope of the report is not therefore as extensive as the title suggests. There are, however, four papers in the report, by M. Mamillan, G. Dawance, A. Moles and J. Jacquesson, of France, which deal in particular with the testing of materials other than concrete, namely, stones, rock and soils.

The three sections of the report cover vibration methods $(A)$, hardness methods $(B)$ and radiographic methods of test $(C)$, respectively. The numbers of papers dealing with these methods vary considerably : there are twenty-six papers in section $A$, nine in section $B$ and four in section $C$. The papers are prefaced by short summaries introducing the sections

* International Union of Testing and Research Laboratories for Materials and Structures (RITEM). Proceedings of the International Symposium on Non-Destructive Testing of Materials and Structures.
Vol. 1, pp. $x+1-208$; Vol. 2, pp. ii $+209-404$. (Paris : RILEM, 12 rue Brancion.) $2,000 \mathrm{fr}$. 
of the report and a general note on research matters requiring further investigation, based on a report prepared by a working-group appointed during the symposium. The summary of section $A$ contains a useful review in tabular form of types and applications of resonance and pulse velocity tests with their advantages and disadvantages. Like most of the papers, however, this summary is more concerned with laboratory tests than with field-tests, and an important omission in regard to the latter is mention of the practical difficulty of measuring path-lengths sufficiently accurately in testing cast in-situ concrete structures by the pulse velocity method. Some of the statements in the second table of this summary should also be interpreted with reserve, particularly the point that the variability of the quality of the concrete within a test specimen or structure can be obtained using the pulse velocity method. This has not yet been satisfactorily established: the variability of the pulse velocity may indicate the variability of the concrete in a structure, since a reduction of the pulse velocity usually indicates a reduction in strength, but relationships between pulse velocity and strength are not closely definable in the field.

The first six papers, from France, South Africa, Japan, United States and Italy, describe apparatus and techniques for measuring the elastic properties of concrete by resonance tests on laboratory specimens in longitudinal and transverse vibration. The paper by N. Stutterheim, J. P. A. Lochner and J. F. Burger (South Africa), including the results of corrosion studies on concrete and cement mortar, is of particular interest, while C. E. Kesler and Y. Higuchi (United States) also contribute a useful paper on experimental problems. The remaining seven papers on resonance tests, from Japan, France, Switzerland and Great Britain, consider the interpretation of test data. A topic common to the majority of these papers is the relationship between the elastic properties and the strength of concrete. The dynamic and static moduli of concrete are compared by J. P. Daxelhofer (Switzerland), R. H. Elvery (Great Britain) and A. Lazard (France), and further remarks on this matter are included by $R$. Gabarat (France), T. Takabayashi (Japan) and F. Arredi (Italy). Daxelhofer's contribution includes observations on the use of resonance tests in studying frost damage to concrete at the Lausanne Polytechnic.

The succeeding thirteen papers of section $A$ are concerned with pulse velocity measurements and their interpretation. Relationships between pulse velocity and the strength of concrete are dealt with by R. Jonos (Great Britain), J. Andersen and P. Nerenst (Denmark), Y. Kameda, K. Awaya and I. Yokoyama (Japan), G. Magnel and G. Huyghe (Belgium) and M. Okushima and Y. Kosaka (Japan), while some information on relationships for stones is given by M. Mamillan. Jones's paper is noteworthy as a summary of much basic research at the Road Research Laboratory, Harmondsworth, and Andersen and Nerenst give a detailed account of their experience using the condenser chronograph developed at the State Testing Laboratory, Copenhagen. These two papers and those by Kameda, Awaya and Yokoyama, by A. Voellmy (Switzerland) and by Magnel and Huyghe, will probably be the papers of most interest to readers concerned with field-work on concrete, and a paper by G. Dawance to readers concerned with field-measurements on rocks. A section in the paper by J. Chefdeville (France) on the detection of faults and cracks supplements Jones's remarks on this subject, and the detection of fire damage is considered by Andersen and Nerenst and in the joint paper by Kameda and his colleagues.

In section $B$, on hardness testing, papers are contributed from Yugoslavia, Germany, Switzerland, Brazil and France, in which countries hardness tests on concrete have received greatest attention. K. Gaede (Germany) and E. Schmidt (Switzerland), prominent workers in this field, present papers describing the use of the Franck, Einbeck and Schmidt hammers, while G. Weil (Germany) points out that the Franck hammer is favoured in Stuttgart. Papers by G. Dawance and D. Jetvic, R. Peltier and P. Meynier describe experience of the use of the Schmidt hammer in France, and P. Vassitch (Yugoslavia) discusses general problems associated with hardness tests and considers both indentation and rebound measurements. A. Voellmy compares results obtained using different types of hammer and by penetration tests, and implies that the Schmidt hammer is preferable to other types. This point is clearly a matter of controversy among workers with experience of hardness testing, however.

The four papers of section $C$ describe radiographic testing techniques that are still in their infancy. With one exception-a short note by G. Huyghe (Belgium) -they deal with research in France. J. Brochard describes and discusses density measurements by gamma-radiation at the Centre Expérimentale de Recherches et d'Études du Bâtimeat et des Travaux Publics and the measurement of water content by neutron bombardment. J. P. Fackler's paper is a detailed account of gamma-ray tests on concrete at the Centre Scientifique et Technique du Bâtiment for the specialist, and J. Jacquesson's paper considers a problem in the technique of measuring soil densities.

The report is a useful and informative account of progress and investigations prior to 1954. It appears that it was decided to omit some of the discussion in the repert, presumably in view of the large number of papers. Presentation of a large number of papers during the symposium had the effect of reducing the time spent on discussing the difficulties attending application of the methods of test and the practical significance of field-test results obtained by them. These matters are vitally important, and determine the value and promise of existing techniques of nondestructive testing in regard to concrete construction.

A. E. SEDDON

\section{TEXTILE INDUSTRIES IN THE UNIVERSITY OF LEEDS}

\section{REPORT FOR 1953-54}

$\mathrm{T}$ HE eightieth report, to the Worshipful Company of Clothworkers of the City of London, of the Advisory Committee of the Departments of Textile Industries and Colour Chemistry and Dyoing, University of Lecds*, covering the session 1953-54, notes that the new building to house the man-made fibres division of the Department was rapidly approaching

* Report to the Worshipful Company of Clothworkers of the City of London of the Advisory Committee on the Departments of Textile Industries and Colour Chemistry and Dyeing in the University of
Leeds, for the Session 1953-54. Pp. 42. (Leeds: The University, 1955.) 